\title{
Educational test scores among adolescents in three-generational households in 20 countries
}

\author{
TANSKANEN, ANTTI O \\ DANIELSBACKA, MIRKKA \\ EROLA, JANI \\ University of Turku, Finland
}

\begin{abstract}
Grandparental presence is often found to associate with improved grandchild wellbeing. However, studies have shown that the effect is not always positive. This could be explained by the fact that in some circumstances grandparents compete with grandchildren over parental time resources. We studied the assumption using data from the Program for International Student Assessment (PISA) from 20 Western countries ( $n=$ 73,346 children at age 15). According to the results grandparental presence was associated with lower levels of parental involvement and decreased educational test scores among adolescents. Moreover, the results indicate that when the parental involvement is lower at the first place the grandparental presence tends to be associated with even weaker child outcomes. Finally, we found support that grandparental co-residence is a mediator of the association between parental involvement and child outcomes. These results are discussed with reference to the local resource competition model.
\end{abstract}

Keywords: Adolescents, grandparents, local resource competition, parental involvement, PISA

\section{Introduction}

Due to increased life expectancy in Western societies the proportion of elderly adults and total number of grandparents are rising (OECD, 2014). Nowadays grandparents and grandchildren have more shared years than ever before (Coall \& Hertwig, 2010; Mare, 2011). In addition, due to decreased fertility rates in modern Western countries (Billari \& Kohler, 2004) grandparents today have fewer grandchildren, which means that they may be able to invest more resources in any particular grandchild. Thus, the grandparents have a great opportunity to influence the life of their grandchildren. Indeed, there is a growing number of evidence showing that in contemporary Western societies grandparental involvement often correlates positively with grandchild development and well-being (e.g., Scholl Perry, 1996; Tanskanen \& Danielsbacka, 2012). 
However, not all studies have found a positive, but rather a negative effect of grandparents. For instance, McLanahan and Sandefur (1994) found that grandparental presence was associated with decreased educational attainments among adolescents in the US. Similarly, using data from 32 countries, Kreidl and Hubatkova (2014) showed that adolescents living in three-generational households had lower educational scores than children from intact families.

A three-generational household refers to a living arrangement where children, parents and grandparents live with each other in the same household. Currently, the amount of three generational households varies remarkably between Western countries. For instance, in Southern European countries approximately at least every fourth adolescent is living in the same household with grandparents, while the proportion of this type of households is less than five per cent in Northern European countries (Kreidl \& Hubatkova, 2014). Central European countries as well as the US, the UK, Australia and New Zealand are placed somewhere between these extremes (Kreidl \& Hubatkova, 2014; see also Pilkauskas \& Martinson, 2014). In the era of welfare state retrenchment there are growing demands to increase the responsibility of the family members to take care of each other's well-being in many Western countries. In practice, this means that three generational households may become more common again, like they were in the beginning of 20th century (Ruggles, 2003). If negative child outcomes are commonplace among these households, this may reduce child wellbeing in the developed societies in general.

Previous studies on three generational households have shown mixed results on the effect of grandparental presence on child well-being (e.g., Deleire \& Kalil, 2002; Dunifon \& Kowaleski-Jones, 2007). One key factor explaining this is the varying age of the grandchildren and, as a consequence, the age of grandparents. The existing research suggests that grandparental presence may benefit infants and toddlers more than adolescent grandchildren (see Coall \& Hertwig, 2010 and responses for discussion). This often results from the grandparents' rather than grandchildren's age: when grandchild is older, also the co-residing grandparent is typically older. Younger grandparents possess more resources that can be invested on grandchildren (e.g., Danielsbacka \& Tanskanen, 2012; Hank \& Buber, 2009), whereas older grandparents are more likely dependent of help and care themselves and are rather help receivers than help providers (Pfeffer, 2014). Thus, one may expect that the grandparental presence may not benefit grandchildren when grandchildren are older because of the age of grandparents themselves.

In this paper we study whether the potential negative effect of grandparental presence can be explained by local resource competition, meaning that in some cases grandparents may compete with grandchildren over limited parental resources. As we discuss below, the local resource competition has been previously applied in traditional or historical contexts, but to our knowledge there are no previous studies that have utilized resource competition perspective in intergenerational family studies using data from contemporary Western societies.

With data from the Program for International Student Assessment (PISA), we in- 
vestigate the educational achievements of 15 -year-old children in 20 Western countries. We use cross-national data, because we expect that the resource competition in families could be a general mechanism that should apply in different institutional settings (see Henrich, Heine \& Norenzayan, 2010 for discussion). However, different social institutions may both moderate as well as mediate the effects of the local resource competition, making it hard to identify its effects in different contexts. Because of this we employ country fixed effect models that allow us to control for the between-country variation.

The study has four goals. First, we are interested in whether living in three-generational households is associated with the amount of parental involvement children receive. Second, we study whether grandparental presence is associated with adolescents' educational achievements. Third, we test whether the presence of grandparents is associated with poorer child outcomes more strongly when the level of parental involvement in children is lower rather than higher. Our theoretical assumption is that grandparental presence is negatively associated with child outcome, because co-residing grandparents might reduce the time that parents give to their children. Thus our final test considers whether the grandparental presence actually mediates the association between parental involvement and child educational outcomes.

All assumptions are based on local resource competition perspective that can explain why in some circumstances grandparental presence has detrimental effects among grandchildren, while in other cases children may benefit from their presence.

\section{Grandparental presence and competition over parental time}

During the last decades the influence of grandparental presence on grandchild wellbeing has achieved increasing attention among sociologists, economists, psychologists and biologists (Coall \& Hertwig, 2010; 2011). Grandparental presence can take two forms, namely custodial grandparent families and three-generational households. In custodial grandparent families (or grandparent headed families) children are living and raised by their grandparents without parental presence. These family arrangements are often shown to be related to family poverty and instability. As a consequence, studies have found that children living in custodial grandparent families have lower levels of well-being compared to children who are living in intact or even single-parent families (see Dunifon, 2013 for a review). In three-generational households children are living with one or both of their parents and grandparent(s). In this study we concentrate on three-generational households, where grandparents may sometimes compete with grandchildren over parental resources.

When grandchildren are infants or toddlers, grandparental support is often found to be associated with improved child outcomes, measured by child development, health and psychological well-being (Sear \& Coall, 2011). In traditional and historical populations grandparental presence is even shown to correlate with increased grandchild 
survival (Sear \& Mace, 2008). Studies have shown that the valuable role of grandparents does not restrict to past populations only but is true also in present-day nations. In contemporary Western societies support received from non-resident grandparents is often found to be associated with improved health and development among grandchildren of different ages (Sear \& Coall, 2011). However, grandparental presence in threegenerational households may not be always beneficial. This has been the case in studies concerning adolescent children, in particular.

Although the US evidence has shown that adolescent children who have lived with single mothers and grandparents in some point of their childhood receive higher educational attainments than children who lived all of their childhood with single mothers only (Aquilino, 1996), several studies have found that when children are adolescents, living with grandparents in three-generational households may not be beneficial for them (e.g. Kreidl \& Hubatkova, 2014; McLanahan \& Sandefur, 1994). The negative effects are not restricted to education alone: a previous US study showed that grandparental presence could have negative health outcomes among adolescent grandchildren (Krueger, Jutte, Franzini, Elo \& Hayward, 2015).

One of the problems of these studies have been that the negative effects of grandparental presence have not been comprehensively theoretically explained. Here we present one potential explanation: that the negative effect may be explained by the local resource competition between grandparents and grandchildren. The local resource competition model emphasizes that family members who belong to the same household unit and who thus are dependent on the same resources may compete over those resources with each other. The competition should exist, in particular, when the resources are scarce (Strassmann et al., 2006; Strassmann \& Garrard, 2011). The basic assumption here is that in three-generation families older grandparents may cease to be net producers, thereby competing for resources with their grandchildren. This competition can have detrimental effects for grandchildren.

Previously, local resource competition between grandparents and grandchildren has been studied in historical and contemporary subsistence societies (e.g., Campbell \& Lee, 1996; Strassmann, 2011; Voland \& Beise, 2002). In subsistence societies such as hunter-gatherers who rely on natural resources to provide for basic needs, the competition between grandparents and grandchildren over local resources have concerned mainly food and other vital resources and the outcome of this competition has been measured by child mortality. However, because of the decreased child mortality rates in modern Western societies the best child outcome indicator may not anymore be child mortality but rather some "softer" type of child outcome, such as developmental and educational achievement (Coall \& Hertwig, 2010). Moreover, in contemporary affluent societies the resources over which to compete are not likely to be food or other vital resources, but rather resource that still is and will remain as finite: parental time. Thus our first hypothesis is: 
Hypothesis 1 (H1): Children who live in three generational households with grandparents receive lower levels of parental involvement than children who do not live with grandparents

Parental involvement is here defined as a time resource that represents a form of social capital that is comparable to other forms of capital, namely economic and cultural capital (e.g., Furstenberg, 2005; McNeal, 1999; Parcel, Dufur \& Zito, 2010). Parental involvement may take place either directly or indirectly. Indirect parental involvement includes, for instance, parental attendance to school and community based activities (Borgonovi \& Montt, 2012). In the present investigation we concentrate on direct parental involvement measured by the communication between parents and children. Previous studies have shown that parent-child communication has a higher positive effect on the child's educational outcomes compared to indirect measures of parental involvement (see Castro, Expósito-Casas, López-Martín, Lizasoain, Navarro-Asencio \& Gaviria, 2015 for review).

Earlier literature has consistently shown that greater parental involvement is associated with improved educational achievements among children in different countries and among different aged children (e.g., Epstein, 2001; Fan \& Chen, 2001; Hango, 2007; Park, 2008; Sénéchal \& Young, 2008). However, if grandparents compete with grandchildren over parental time, grandparental presence may diminish the time parents are able to invest in their children. Because of this grandparental presence should also have negative influence on educational outcomes of the children. Our second prediction is that:

Hypothesis 2 (H2): Adolescent children living with grandparents in three-generational households receive lower educational test scores than children who are not living with grandparents

The local resource competition model also predicts that the competition between grandparents and grandchildren should be harder when the resources are lower rather than higher (Strassmann et al., 2006; Strassmann \& Garrard, 2011). Consider an example of two families were parents have up to ten and up to four hours spare time that they can invest entirely on their children if there are no dependent grandparents in the household. However, if there is a dependent grandparent living with them who necessarily needs two hours of parents' time, this means that in the first example parents have still eight hours to invest in the children whereas in the second example they have only two hours left. The loss of parental time should be clearly more detrimental for the children in the latter case. Thereby we expect that:

Hypothesis 3 (H3): Grandparental presence is more negatively associated with outcomes in adolescents when parental involvement is lower than higher 


\section{Other relevant factors}

Based on the local resource competition perspective, one can assume that grandparental presence should influence both parental involvement and educational attainments among children. In previous studies, several variables are shown to correlate with both parental involvement and educational achievement in children, and, thus, it is important to control for these potentially confounding variables to attain more robust results.

With respect to gender, researches have consistently shown that girls receive higher scores in educational tests than boys (e.g., Hampden-Thompson, 2009; Kreidl \& Hubatkova, 2014). Child's gender may also influence parental involvement (e.g., Lundberg, 2005; Raley \& Bianchi, 2005). Older children are shown to receive higher educational scores than younger ones (e.g., Karwath et al., 2014) and children's age tends to influence also parental involvement (Waldfogel, 2006). When the number of siblings in household increases, the amount of time parents are able to invest in any particular child tends to decrease (e.g., Downey, 2001; Coleman, 1988). Increased number of siblings is also associated with decreased level of educational test scores (e.g., Jaeger, 2008; Sieben, Huinink \& de Graaf, 2001). In addition, birth order has been shown to associate with educational achievements among children in the way that first born children (including children without siblings) tend to receive higher academic attainments compared to later born children (e.g., Blake, 1989; Conley \& Glauber, 2006). Birth order may also influence the amount of parental involvement, although this may be related to the age and the gender of the children (e.g., Salmon, 1999; 2003).

In the case of children's educational attainments, the language spoken at home is a relevant factor, because previous studies have shown that children who are speaking the test language in home receive higher scores than children who are not speaking the test language in their home (e.g., Hampden-Thompson, 2009). Moreover, language spoken at home may at least partly control for the ethnic background that is shown to associate with educational scores among adolescents in previous studies (Dunifon, 2013). Previous studies have shown that compared to two-parent families, in single parent families children tend to receive lower scores in educational tests (e.g. Astone \& McLanahan, 1991; Biblarz \& Gottainer, 2000). In addition, family dynamics and the amount of parental involvement may significantly differ between single and two parent families (e.g., Amato, 2001; Anderson, 2011). Finally, parental socioeconomic and cultural resources are consistently shown to associate with both educational scores in children and parental involvement (e.g., Castro et al., 2015; Downey, 2001).

\section{Data and methods}

To study the three hypotheses we use first-round data from the Program for International Student Assessment (PISA) that was collected in 2000. The goal of the PISA is to collect cross-national data on 15-year-old children's educational achievements. In our case we 
can only apply the first round of the PISA because only it contains information on the presence of grandparents.

In 2000, the PISA data were collected from 32 countries but in the present analyses we concentrate on the 20 Western countries included. These countries are Italy, Spain, Greece, Portugal, Germany, Switzerland, Austria, Luxembourg, Belgium, France, the UK, Ireland, Finland, Norway, Sweden, Denmark, Australia, New Zealand, the US and Canada $^{1}$. We restricted the analyses to these industrialized Western countries in order to have societies with relatively similar rates of social, political and economic development as well several cultural similarities. In addition, the PISA data includes only children who were in school at age 15 . In the developing countries only half of the population or less attend secondary schools at that age, and by selecting only more developed industrial countries we should be able to avoid some issues related to background selection and response bias. Despite the country restrictions we were still left with data on 73,346 adolescents.

First we investigate whether children living with grandparents receive lower amount of parental involvement compared to children living without grandparents. In PISA direct parent-child communication is measured by five questions that indicated two dimensions of parental involvement, namely cultural and social communication. We use these direct measures of involvement because previous studies have shown that they tend to have higher positive effect on the child's educational outcomes compared to indirect measures of parental involvement (see Castro et al., 2015 for a review). These measures of involvement require spending time with the child so they can be interpreted also as a use of time resources in favor of the child. In the questionnaire children were asked to report by five-point scale (ranging from $1=$ never or hardly ever to $5=$ several times a week): How often they have discussed social or political issues with parents? How often they have discussed about books, films or television programs with parents? How often they have discussed with parents how well they are doing at the school? How often they have eaten the main meal together with parents around the table? How often they spend time to just talking with parents? The parental involvement variable was constructed by summing up the answers in these five questions (Cronbach's alpha $=0.66$ ).

Child outcomes are measured with educational test scores. In PISA, students' school attainments are measured through three indicators, namely reading literature, mathematical literacy and scientific literacy. In every PISA round, one of these themes is selected as the main theme. In PISA 2000, the main point was to measure students' reading literature skills. Mathematical and scientific literacy were also tested, although not all of the students participated in these tests. Reading skills are measured through students' capability to use, understand and reflect written text (OECD, 2001). The PISA

1 The Netherlands was not included, because the Dutch data did not fulfill the PISA standards. 
sample contains five plausible values for reading literature for each respondent - also for those who have not actually taken that part of the test - with a mean score of 500 and a standard deviation of 100 . These plausible values were constructed by the PISA project team by using Item Response Theory, and they represent a selection of probable attainment for the students. The estimation of the plausible reading literature scores was done five times, once for each variable (see Adams \& Wu, 2002 for full information). In the sample of 20 more affluent societies, the mean score of reading literature was $528(\mathrm{SD}=91.86)$.

The main independent variable measures whether children co-reside with grandparents. In the questionnaire, all students were asked to report whether grandparent(s) usually live in the same home with them. Unfortunately, the data does not include information on the number of co-residing grandparents or any characteristics on grandparental level (e.g., gender, age, or health). There are major differences in the amount of three generational households between countries. In our study sample the amount of co-residing grandparents varies from $2.6 \%$ in Finland to $31.6 \%$ in Italy (Appendix Table 1).

In the analyses, we controlled for several potential confounding variables discussed above that have been shown to correlate with parental involvement and children's educational attainments in previous studies. These are children's gender, age (in months), number of siblings, birth order, the language spoken at home (i.e., whether the children were speaking the test language at home), family structure (intact or lone-parent), parental education (i.e., the highest level of education between parents indicated by ISCED-97 classification where lower numbers indicate lower educational level, and higher numbers indicate the opposite), parental occupation (measured by the highest status of occupation between the parents and the index ranged from 16 to 90 where lower scores indicate lower occupational status, and higher scores indicate the opposite) and number of books at home (i.e., cultural capital). The sample descriptive statistics are presented in Table 1. 
Table 1. Descriptive statistics

$(\% /$ mean $)$

\begin{tabular}{lll}
\hline & $\% /$ mean SD \\
Child's gender (\%) & & \\
Girl & 49.9 & \\
Boy & 50.1 & \\
Child's age in months (mean) & 188.7 & 3.44 \\
Child's number of siblings (mean) & 1.7 & 1.18 \\
Child's birth order (\%) & & \\
First born & 42.1 & \\
Later born & 57.9 \\
Language spoken at home (\%) & \\
Otherwise & 10.1 \\
Speak test language at home & 89.9 \\
Family structure (\%) & \\
Intact & 84.5 \\
$\quad$ Lone-parent & 15.5 \\
Parental education (\%) & \\
ISCED 1 & 0.6 \\
ISCED 2 & 5.8 \\
ISCED 3 & 12.1 \\
ISCED 4 & 13.6 \\
ISCED 5 & \\
ISCED 6 & 22.0 \\
Parental occupation (mean) & 45.9 \\
Number of books at home (\%) & 50.2 \\
None & \\
1-10 & 1.1 \\
11-50 & 6.5 \\
51-100 & 19.0 \\
101-250 & 21.5 \\
251-500 & 22.7 \\
More than 500 & 16.8 \\
\hline $\mathrm{n}=73,346$ & 12.5 \\
\end{tabular}

We employ ordinary least squares regression models with fixed effects that controlled for between-country variation. While studying educational test scores among children we used the statistical software Stata's pv package to analyze the plausible values of reading literature ('pv' command in Stata; see Macdonald, 2014). In all analyses, several of the potential confounding variables that were described above were controlled for.

\section{Results}

Grandparental presence and parental involvement

We expected that children who live in three generational households receive lower levels of parental involvement compared to children who do not live in three generational households (H1). In line with the prediction we found that children living with grandparents receive lower amount of parental involvement than children living without grandparents (Table 2). 
Table 2. Factors associated with parental involvement ( $\beta$-coefficients from regression model) (country fixed effects)

\begin{tabular}{|c|c|c|c|c|}
\hline & $\beta$ & SE & $\mathrm{t}$ & $\mathrm{p}$ \\
\hline \multicolumn{5}{|l|}{ Grandparent in household } \\
\hline No & ref & & & \\
\hline Yes & -0.14 & 0.04 & -3.17 & 0.002 \\
\hline \multicolumn{5}{|l|}{ Child's gender } \\
\hline Girl & ref & & & \\
\hline Boy & -0.63 & 0.03 & -22.84 & $<0.001$ \\
\hline Child's age in months & 0.02 & 0.004 & 4.69 & $<0.001$ \\
\hline Child's number of siblings & -0.15 & 0.01 & -11.54 & $<0.001$ \\
\hline \multicolumn{5}{|l|}{ Child's birth order } \\
\hline First born & ref & & & \\
\hline Later born & -0.47 & 0.03 & -15.62 & $<0.001$ \\
\hline \multicolumn{5}{|l|}{ Language spoken at home } \\
\hline Otherwise & ref & & & \\
\hline Speak test language at home & 0.10 & 0.05 & 2.06 & 0.040 \\
\hline \multicolumn{5}{|l|}{ Family structure } \\
\hline Intact & ref & & & \\
\hline Lone-parent & -0.57 & 0.04 & -14.86 & $<0.001$ \\
\hline \multicolumn{5}{|l|}{ Parental education } \\
\hline ISCED 1 & ref & & & \\
\hline ISCED 2 & 0.88 & 0.19 & 4.74 & $<0.001$ \\
\hline ISCED 3 & 0.92 & 0.18 & 5.09 & $<0.001$ \\
\hline ISCED 4 & 1.23 & 0.18 & 6.76 & $<0.001$ \\
\hline ISCED 5 & 1.14 & 0.18 & 6.30 & $<0.001$ \\
\hline ISCED 6 & 1.47 & 0.18 & 8.17 & $<0.001$ \\
\hline Parental occupation & 0.02 & 0.001 & 16.36 & $<0.001$ \\
\hline \multicolumn{5}{|l|}{ Number of books at home } \\
\hline None & ref & & & \\
\hline $1-10$ & 1.59 & 0.15 & 10.98 & $<0.001$ \\
\hline $11-50$ & 2.47 & 0.14 & 17.84 & $<0.001$ \\
\hline $51-100$ & 3.06 & 0.14 & 22.11 & $<0.001$ \\
\hline $101-250$ & 3.50 & 0.14 & 25.27 & $<0.001$ \\
\hline $251-500$ & 3.96 & 0.14 & 28.33 & $<0.001$ \\
\hline More than 500 & 4.31 & 0.14 & 30.39 & $<0.001$ \\
\hline R2 & 0.13 & & & \\
\hline
\end{tabular}

Table 2 shows that also several other factors are associated with parental involvement. Girls and older children tend to receive higher levels of involvement than boys and younger children. When number of siblings increases parental involvement decreases. First born children report higher levels of parental involvement compared to later born children. Group "speaks test language at home" received higher amount of parental involvement than others. Moreover, children from intact families received higher level of involvement compared to children from lone-parent families. Finally, children from higher socio-economic and cultural status families received more involvement than children in lower status families.

\section{Grandparental presence and educational achievements among children}

Table 3 shows that children living in three generational households receive lower educational test scores than others. This finding is in line with our prediction (H2). Appen- 
dix Table 2 shows that in 19 countries out of 20 grandparental presence is associated with decreased educational test scores among children. In these 19 countries the effect magnitudes varied from -65.3 (New Zealand) to -8.5 (Spain). The only exception to this general trend was Finland, where we found a marginally significant effect showing that children living in three generational households received higher scores than children living only with their parents.

Also several other factors were associated with reading literature test scores among children (Table 3). Girls received higher scores than boys and when the age of the children increased so did the educational test scores. When parental involvement increases so do the test score among children. Increased number of siblings correlated with decreased scores and first born children received higher scores than later born children. Children from intact families earned higher scores than children from lone-parent families. Those who speak test language in home received higher scores than those who speak some other language. In addition, children with higher socio-economic and cultural status of families earned higher scores than children with lower family status.

\begin{tabular}{|c|c|c|c|c|}
\hline & $\beta$ & SE & $\mathrm{t}$ & $\mathrm{p}$ \\
\hline \multicolumn{5}{|l|}{ Grandparent in household } \\
\hline No & ref & & & \\
\hline Yes & -21.87 & 0.98 & -22.40 & $<0.001$ \\
\hline Parental involvement & 3.62 & 0.08 & 43.53 & $<0.001$ \\
\hline \multicolumn{5}{|l|}{ Child's gender } \\
\hline Girl & ref & & & \\
\hline Boy & -26.76 & 0.61 & -43.97 & $<0.001$ \\
\hline Child's age in months & 1.70 & 0.09 & 18.29 & $<0.001$ \\
\hline Child's number of siblings & -4.11 & 0.30 & -13.90 & $<0.001$ \\
\hline \multicolumn{5}{|l|}{ Child's birth order } \\
\hline First born & ref & & & \\
\hline Later born & -10.69 & 0.65 & -16.35 & $<0.001$ \\
\hline \multicolumn{5}{|l|}{ Language spoken at home } \\
\hline Otherwise & ref & & & \\
\hline Speak test language at home & 24.07 & 1.15 & 20.88 & $<0.001$ \\
\hline \multicolumn{5}{|c|}{ Family structure } \\
\hline Intact & ref & & & \\
\hline Lone-parent & -4.16 & 0.85 & -4.92 & $<0.001$ \\
\hline \multicolumn{5}{|l|}{ Parental education } \\
\hline ISCED 1 & ref & & & \\
\hline ISCED 2 & 18.83 & 4.26 & 4.42 & $<0.001$ \\
\hline ISCED 3 & 20.00 & 4.13 & 4.85 & $<0.001$ \\
\hline ISCED 4 & 33.03 & 4.24 & 7.80 & $<0.001$ \\
\hline ISCED 5 & 36.19 & 4.16 & 8.70 & $<0.001$ \\
\hline ISCED 6 & 35.87 & 4.24 & 8.46 & $<0.001$ \\
\hline Parental occupation & 1.06 & 0.02 & 45.98 & $<0.001$ \\
\hline \multicolumn{5}{|l|}{ Number of books at home } \\
\hline None & ref & & & \\
\hline $1-10$ & 23.34 & 3.22 & 7.26 & $<0.001$ \\
\hline $11-50$ & 48.51 & 3.23 & 15.04 & $<0.001$ \\
\hline $51-100$ & 60.75 & 3.19 & 19.02 & $<0.001$ \\
\hline $101-250$ & 76.85 & 3.14 & 24.50 & $<0.001$ \\
\hline $251-500$ & 87.00 & 3.21 & 27.07 & $<0.001$ \\
\hline More than 500 & 87.98 & 3.33 & 26.41 & $<0.001$ \\
\hline $\mathrm{R} 2$ & 0.28 & & & \\
\hline
\end{tabular}

$n=73,346$ 
We also expected that grandparental presence is associated with child educational outcomes more negatively when parental involvement is lower rather than higher (H3). The results from a model with an interaction term between parental involvement and grandparental presence are depicted in Figure 1. We found that the difference in educational test scores between those who lived with their grandparents and those who did not was larger among children who received lower amount of parental involvement compared to those who received higher amount of involvement $(\beta=0.73, \mathrm{SE}=0.22, \mathrm{t}$ $=3.37, \mathrm{p}<0.001, \mathrm{n}=73,346, \mathrm{R} 2=0.28$ ). Figure 1 shows that, for instance, when children reported lowest level of parental involvement the difference between those who lived with grandparents and those who did not was 32 points. When the highest level of parental involvement existed the difference was 18 points. These findings were in accordance with our third hypothesis.

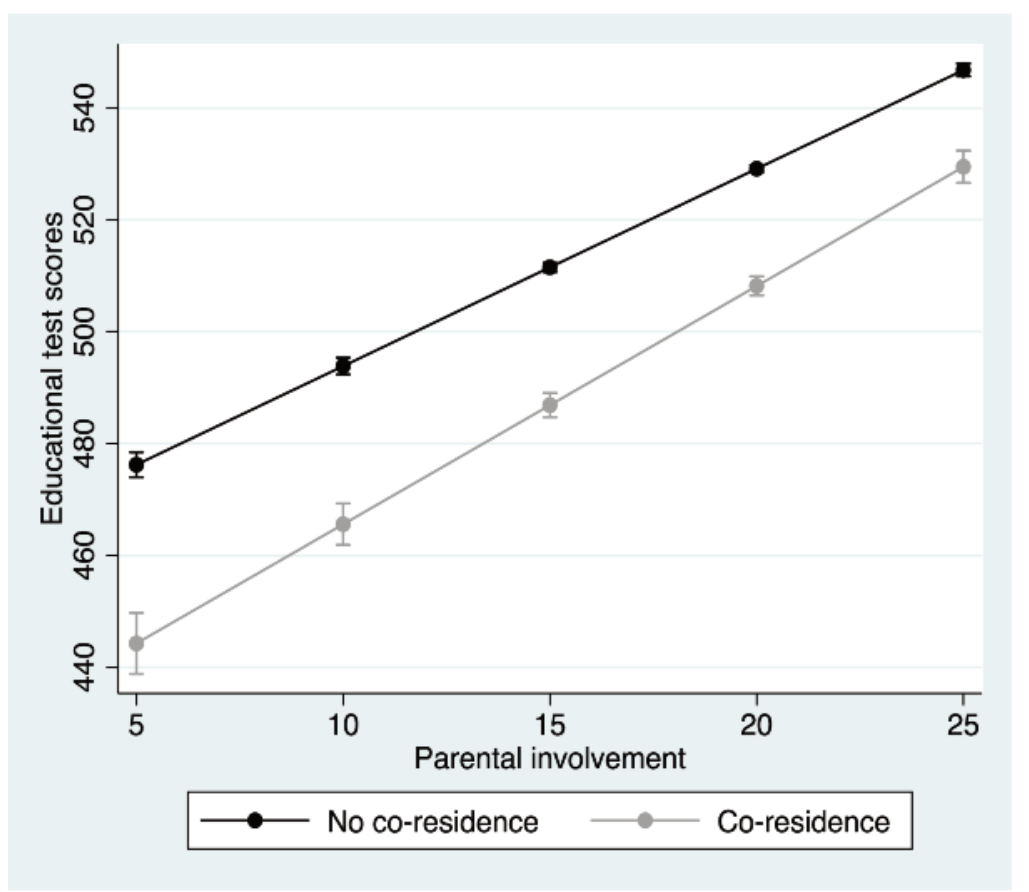

Figure 1. Association between children's educational scores and parental involvement by grandparental co-residence (predicted margins and $95 \%$ confidence intervals) (country fixed effects)

Note. Control variables: Child's gender, age in months, child's number of siblings, child's birth order, language spoken at home, family structure, parental education, parental occupation and number of books at home. 
Then, we investigated whether we can find evidence that co-resident grandparents distract parents from their children, lowering parental involvement, and in turn lowering academic achievements among children (results not shown in tables or figures). We found that the unadjusted $\beta$-coefficient between grandparental presence and educational scores in children decreased from -32.0 to -29.7 after parental involvement was controlled for. This indicates that parental involvement could be a mediator between grandparental presence and child's academic achievement. To formally test whether parental involvement mediates the association between grandparental presence and child educational scores, a Sobel z-test for mediation was conducted. In the mediation test the adjusted coefficients were used. According to the test, parental involvement is a mediator between grandparental co-residence and child outcomes (Coef. $=7.53$; $\mathrm{SE}=0.01 ; \mathrm{p}<.001$ ).

Finally, for sensitivity purposes we investigated whether the negative association between grandparental presence and child achievements varies by the level of parental resources (results not shown in tables or figures). To study this we included interaction terms in the models and investigated the interactions between parental resources (measured by parental education, occupation and number of books at home) and grandparental presence. We found that in families with lower parental educational level $(\beta=$ $-0.12, \mathrm{SE}=0.06, \mathrm{p}=0.048)$ and lower occupational status $(\beta=-4.18, \mathrm{SE}=0.74, \mathrm{p}<$ $0.001)$ the grandparental presence was more negatively associated with educational test scores compared to higher resource families. Similar effect was not found in the case of cultural capital measured by number of books at home.

\section{Discussion and conclusions}

In the present study we investigated the associations between grandparental presence and parental involvement as well as grandparental presence and educational outcomes among children. We have tested three hypotheses based on the assumption that in three generational households grandparents can compete with grandchildren over parental time resources, which may cause detrimental effects for children. Moreover, it is assumed that the competition is more severe when overall parental involvement is lower than higher.

First, we found that children who lived in three generational households with grandparents received lower levels of parental involvement than children who did not live in three generational households. This is in contrast with the finding by Pong and Chen (2010) who showed with Taiwanese data that parental involvement (measured by parent-child communication) was not lower or higher in three-generational than two-generational households. Second, our results showed that children who were living with their grandparents received lower educational test scores than children who were not living with grandparents. This finding is in line with two previous studies of the association between grandparental co-residence and educational scores among adolescents (Kreidl \& Hubatkova, 2014; McLanahan \& Sandefur, 1994). 
Third, we found that grandparental presence was more negatively associated with educational attainments in adolescents when parental involvement was lower. The gap in educational attainments between those who lived with their grandparents and those who did not was larger among children who received lower amounts of parental involvement compared to those who received higher amounts of involvement. Moreover, according to the Sobel z-test for mediation, grandparental presence mediated the association between parental involvement and child educational test scores.

Even though we found that in general co-residing with grandparents is associated with lower educational test scores among 15-year-old children, several previous studies have shown that the involvement of non-resident grandparents often correlate with improved child outcomes also in the case of adolescent grandchildren (e.g., Attar-Schwartz et al., 2009; Tanskanen \& Danielsbacka, 2012). The local resource competition perspective may provide an explanation for these seemingly conflicting findings. When grandparents do not live in the same household with grandchildren they could be "child saviors" in the sense that their involvement has beneficial outcomes for grandchildren (Arber \& Timonen, 2012). In these circumstances they may endow resources to grandchildren, which in turn could improve the child well-being. In contrast, when grandparents (in their older age, in particular) live in the same household with grandchildren they can rather lessen the amount of resources than append them. Thus, grandparental presence can have detrimental effects for grandchildren.

In addition, the local resource competition perspective can explain previous results, which have shown that the effect of grandparental resources on socioeconomic success of their grandchildren is often negligible once parental resources are taken into account (e.g., Erola \& Moisio, 2007; Jaeger, 2012; Warren \& Houser, 1997). These previous results are based on studies that have included both co-resident and non-resident grandparents. This may have had influence on the results, because co-residing and non-residing grandparents can have opposite impacts on grandchild well-being. By investing resources in their offspring, non-resident grandparents can improve adolescent grandchildren's well-being (Sear \& Coall, 2011) but co-resident grandparents could rather diminish than improve the well-being, as we have been shown in the present study. Thus, we argue that in future studies it is important to investigate the effect of co-resident and non-resident grandparents separately.

Here, we have used cross-national data from 20 Western countries and employed country fixed effect models controlling for between-country variation. This methodological approach was used because we wanted to find a general mechanism that is not associated only with some country-specific feature (see Henrich et al., 2010 for discussion). Although country comparison was not the focus here, we think that it is important to study resource competition also from a comparative perspective. Thus, we call for future studies that would try to explain the between country differences more explicitly.

Limitations of the present study include that we do not know whether the grandparents are recent arrivals or whether they have been long standing members of households, 
which may influence resource competition. Moreover, the PISA data does not include grandparental level variables and, thus, we were unable to identify whether children co-resided with their grandmothers or grandfathers or maternal or paternal grandparents. This is a limitation because previous studies have shown that different grandparent types may affect child outcomes differently (e.g., Coall \& Hertwig, 2010; Sear \& Mace, 2008). In addition, the lack of grandparental level variables means that the PISA data does not have information on grandparental age or health, factors that could potentially influence the resource competition. Older grandparents with poorer health may compete over parental time resources more than younger and healthier ones. Moreover, younger and healthier grandparents could be more able to provide support to other family members (e.g., Danielsbacka \& Tanskanen, 2012; Hank \& Buber, 2012).

Finally, due to the fact that PISA data are cross-sectional rather than longitudinal our study has two important limitations. First, it could be that our findings result from between-person rather than from within-person differences, meaning that those who live in three-generational households have poorer outcomes because of the other associated family disadvantages and not that grandparental presence would have a negative impact. In order to provide more causal evidence the topic could be studied using longitudinal fixed-effect models focusing on within-person variation in exposure and excluding between-person effects (Curran \& Bauer, 2011). Second, we have only studied the educational scores of 15 -year-old children, while grandparental effects may vary between different-aged grandchildren. Thus, we call for future studies to analyze the effect of grandparental co-residence during the life course of their grandchildren.

To conclude, our results show that grandparental presence is associated with lower levels of parental involvement and decreased educational scores among adolescents. We also showed that grandparental presence may have a more negative effect on child outcomes when the amount of parental involvement is lower rather than higher. We hope that these findings stimulate future studies to explore kin relations by considering the resource competition between family members over limited resources.

\section{Acknowledgements}

This research was supported by the European Research Council, decision number ERC2013-CoG-617965; and the Strategic Research Council of the Academy of Finland, decision number 293103. 


\section{References}

Amato, P. R. (2000). The consequences of divorce for adults and children. Journal of Marriage and Family, 62, 1269-1287. https://doi.org/10.1111/j.1741-3737.2000.01269.x

Anderson, K. G. (2011). Stepparenting, divorce, and investment in children. In C. A. Salmon, \& T. K. Shackelford (Eds.), The Oxford Handbook of Evolutionary Family Psychology, pp. 97-112. New York: Oxford University Press. https://doi.org/10.1093/oxfordhb/9780195396690.013.0007

Aquilino, W. S. (1996). The life course of children born to unmarried mothers: Childhood living arrangements and young adult outcomes. Journal of Marriage and the Family, 58, 293-310. https://doi.org/10.2307/353496

Arber, S., \& Timonen, V. (2012). Contemporary Grandparenting: Changing Family Relationships in Global Contexts. Chicago: Policy Press. https://doi.org/10.1332/policypress/9781847429681.001.0001

Astone N.M., \& McLanahan, S. (1991). Family structure, parental practices, and high school completion. American Sociological Review, 56, 309-320. https://doi.org/10.2307/2096106

Attar-Schwartz, S., Tan, J.-P., Buchanan, A., Flouri, E., \& Griggs, J. (2009). Grandparenting and adolescent adjustment in two-parent biological, lone-parent, and step-families. Journal of Family Psychology, 23, 67-75. https://doi.org/10.1037/a0014383

Biblarz, T. J., \& Gottainer, G. (2000). Family structure and children's success: A comparison of widowed and divorced single-mother families. Journal of Marriage and Family, 62, 533-548. https://doi.org/10.1111/j.1741-3737.2000.00533.x

Billari, F. C., \& Kohler, H-P. (2004). Patterns of low and lowest-low fertility in Europe. Population Studies, 58, 161-176. https://doi.org/10.1080/0032472042000213695

Blake, J. (1989). Family size and achievement. Berkeley: University of California Press.

Borgonovi, F., \& Montt, G. (2012). Parental involvement in selected OECD countries and economics. OECD Education Working Paper number 73. Paris: OECD.

https://doi.org/10.1787/5k990rk0jsjj-en

Bourdieu, P. (1977). Reproduction in Education, Society, and Culture. Beverly Hills: Sage.

Bourdieu, P. (1984). Distinction. A Social Critique of the Judgement of Taste. Cambridge, MA: Harvard University Press.

Campbell, C., \& Lee, J. Z. (1996). A death in the family: Household structure and mortality in rural Liaoning: Life-event and time-series analysis, 1792-1867. The History of the Family, 1, 297-328. https://doi.org/10.1016/S1081-602X(96)90026-3

Castro, M., Expósito-Casas, E., López-Martín, E., Lizasoain, L., Navarro-Asencio, E., \& Gaviria, J. L. (2015). Parental involvement on student academic achievement: A meta-analysis. Educational Research Review, 14, 33-46. https://doi.org/10.1016/j.edurev.2015.01.002

Coall, D. A., \& Hertwig, R. (2010). Grandparental investment: Past, present and future. Behavioral and Brain Sciences, 33, 1-56. https://doi.org/10.1017/S0140525X09991105

Coall, D.A., \& Hertwig, R. (2011). Grandparental investment: A relic of the past or a resource for the future? Current Directions in Psychological Science, 20, 93-98.

https://doi.org/10.1177/0963721411403269

Coleman, J. S., (1988). Social capital in the creation of human capital. American Journal of Sociology, 94, 95-120. https://doi.org/10.1086/228943

Conley, D., \& Glauber, R. (2006). Parental educational investment and children's academic risk: Estimates of the impact of sibship size and birth order from exogenous variations in fertility. Journal of Human Resources, 41, 722-737. https://doi.org/10.3368/jhr.XLI.4.722 
Curran P.J. \& Bauer D.J. (2011). The disaggregation of within-person and between-person effects in longitudinal models of change. Annual Review of Psychology, 62, 583-619. https://doi.org/10.1146/annurev.psych.093008.100356

Danielsbacka, M., \& Tanskanen, A.O. (2012). Adolescent grandchildren's perceptions of grandparents' involvement in UK: An interpretation from life course and evolutionary theory perspective. European Journal of Ageing, 9, 329-341. https://doi.org/10.1007/s10433-012-0240-x

Deleire, T., \& Kalil, A. (2002). Good things come in threes: Singleparent multigenerational family structure and adolescent adjustment. Demography, 39, 393-413. https://doi.org/10.1353/dem.2002.0016

Downey, D. B. (2001). Number of siblings and intellectual development: The resource dilution explanation. American Psychologist, 56, 497-504. https://doi.org/10.1037/0003-066X.56.6-7.497

Dunifon, R. (2013). The influence of grandparents in the lives of children and adolescents. Child Development Perspectives, 7, 55-60. https://doi.org/10.1111/cdep.12016

Dunifon, R., \& Kowaleski-Jones, L. (2007). The influence of grandparents in single-mother families. Journal of Marriage and Family, 69, 465-481. https://doi.org/10.1111/j.17413737.2007.00377.x

Epstein, J. L. (2001). School, Family, and Community Partnerships: Preparing Educators and Improving Schools. Boulder, CO: Westview.

Erola, J., \& Moisio, P. (2007). Social mobility over three generations in Finland, 1950-2000. European Sociological Review, 23, 169-183. https://doi.org/10.1093/esr/jcl027

Fan, X., \& Chen, M. (2001). Parental involvement and students' academic achievement: A metaanalysis. Educational Psychology Review, 13, 1-22. https://doi.org/10.1023/A:1009048817385

Furstenberg, F. F. (2005). Banking on families: How families generate and distribute social capital. Journal of Marriage and Family, 67, 809-821. https://doi.org/10.1111/j.17413737.2005.00177.x

Hampden-Thompson, G. (2009). Are two better than one? A comparative study of achievement gaps and family structure. Compare, 39, 517-534. https://doi.org/10.1080/03057920802366372

Hango, D. (2007). Parental investment in childhood and educational qualifications: Can greater parental involvement mediate the effects of socioeconomic disadvantage? Social Science Research, 36, 1371-1390. https://doi.org/10.1016/j.ssresearch.2007.01.005

Hank, K., \& Buber, I. (2009). Grandparents caring for their grandchildren: Findings from the 2004 survey of health, ageing, and retirement in Europe. Journal of Family Issues, 30, 53-73. https://doi.org/10.1177/0192513X08322627

Henrich, J., Heine, S. J., and Norenzayan, A. (2010).The weirdest people in the world? Behavioral and Brain Sciences, 33, 61-83. https://doi.org/10.1017/S0140525X0999152X

Jaeger, M. (2008). Do large sibships really lead to lower educational attainment? New evidence from quasi-experimental variation in couples' reproductive capacity. Acta Sociologica, 51, 217-235. https://doi.org/10.1177/0001699308094167

Jæger, M. (2012). The extended family and children's educational success. American Sociological Review, 77, 903-922. https://doi.org/10.1177/0003122412464040

Karwath, C., Relikowski, I., \& Schmitt, M. (2014). Sibling structure and educational achievement: How do the number of siblings, birth order, and birth spacing affect children's vocabulary competences? Journal of Family Research, 26, 372-396. https://doi.org/10.3224/zff.v26i3.18993

Kreidl, M., \& Hubatkova, B. (2014). Does coresidence with grandparents reduce the negative association between sibship size and reading test scores? Research in Social Stratification and Mobility, 38, 1-17. https://doi.org/10.1016/j.rssm.2014.04.001

Krueger, P. M., Jutte, D. P., Franzini, L., Elo, I., \& Hayward, M. D. (2015). Family structure and multiple domains of child well-being in the United States: A cross-sectional study. Population Health Metrics, 13:6. https://doi.org/10.1186/s12963-015-0038-0 
Macdonald, K. (2014). PV: Stata module to perform estimation with plausible values. Statistical Software Components, Boston College: Department of Economics.

Mare, R. D. (2011). A multigenerational view of inequality. Demography, 48, 1-23. https://doi.org/10.1007/s13524-011-0014-7

McLanahan, S., \& Sandefur, G. (1994). Growing up with a Single Parent: What Hurts, What Helps? Cambridge, MA: Harvard University Press.

McNeal, R. B. (1999). Parental involvement as social capital: Differential effectiveness on science achievement, truancy, and dropping out. Social Forces, 78, 117-144. https://doi.org/10.2307/3005792

Adams, R., \& Wu, M. (2002). PISA 2000 Technical Report. Paris: OECD.

OECD. (2001). Knowledge and skills for life: First results from PISA 2000. Paris: OECD. https://doi.org/10.1787/9789264195905-en

OECD. (2014). Family database. Paris: OECD.

Park, H. (2008). Home literacy environments and children's reading performance: A comparative study of 25 countries. Educational Research and Evaluation, 14, 489-505. https://doi.org/10.1080/13803610802576734

Pfeffer, F. (2014). Multigenerational approaches to social mobility: A multifaceted research agenda. Research in Social Stratification and Mobility, 35, 1-12. https://doi.org/10.1016/j.rssm.2014.01.001

Pilkauskas, N. V., \& Martinson, M. L. (2014). Three-generation family households in early childhood: Comparisons between the United States, the United Kingdom, and Australia. Demographic Research, 60, 1639-1652. https://doi.org/10.4054/DemRes.2014.30.60

Pong S. L, \& Chen V. W. (2010). Co-resident grandparents and grandchildren's academic performance in Taiwan. Journal of Comparative Family Studies, 41, 111-129.

Raley, S., \& Bianchi, S. (2005). Sons, daughters and family processes: Does gender of children matter? Annual Review of Sociology, 32, 401-421. https://doi.org/10.1146/annurev.soc.32.061604.123106

Ruggles, S. (2003). Multigenerational families in nineteenth-century America. Continuity and Change, 18, 139-165. https://doi.org/10.1017/S0268416003004466

Salmon, C. A. (1999). On the impact of sex and birth order on contact with kin. Human Nature, 10, 183-197. https://doi.org/10.1007/s12110-999-1014-9

Salmon, C. A. (2003). Birth order and relationships: friends, family, sexual partners. Human Nature, 14, 73-81. https://doi.org/10.1007/s12110-003-1017-x

Scholl Perry, K. (1996). Relationships among adolescents' ego development, their academic achievement, and the amount of their contact with and social distance from grandparents. ETD Collection for Pace University, Paper AAI9701161.

Sear, R., \& Coall, D.A. (2011). How much does family matter? Cooperative breeding and the demographic transition. Population and Development Review, 37, 81-112. https://doi.org/10.1111/j.1728-4457.2011.00379.x

Sear, R., \& Mace, R. (2008). Who keeps children alive? A review of the effects of kin on child survival. Evolution and Human Behavior, 29, 1-18. https://doi.org/10.1016/j.evolhumbehav.2007.10.001

Sénéchal, M., \& Young, L. (2008). The effect of family literacy interventions on children's acquisition of reading from kindergarten to grade 3: A meta-analytic review. Review of Educational Research, 78, 880-907. https://doi.org/10.3102/0034654308320319

Sieben, I., Huinink, J., \& de Graaf, P. M. (2001). Family background and sibling resemblance in educational attainment. Trends in the former FRG, the former GDR, and the Netherlands. European Sociological Review, 17, 401-430. https://doi.org/10.1093/esr/17.4.401 
Strassmann, B. I. (2011). Cooperation and competition in a cliff-dwelling people. Proceedings of the National Academy of Sciences of the United States of America, 108, 10894-10901. https://doi.org/10.1073/pnas.1100306108

Strassmann, B. I., \& Garrard, W. M. (2011). Alternatives to the grandmother hypothesis: A metaanalysis of the association between grandparental and grandchild survival in patrilineal populations. Human Nature, 22, 201-222. https://doi.org/10.1007/s12110-011-9114-8

Strassmann, B. I., Hug, B. F., \& Welch, K. (2006). A new twist on the grandmother hypothesis: adverse impact of paternal grandmothers on Dogon grandsons. American Journal of Human Biology, 18, 275-276.

Tanskanen, A. O., \& Danielsbacka, M. (2012). Beneficial effects of grandparental involvement vary by lineage in the UK. Personality and Individual Differences, 53, 985-988. https://doi.org/10.1016/j.paid.2012.07.019

Waldfogel, J. (2006). What Children Need. Cambridge, MA: Harvard University Press.

Warren, J. R., \& Hauser, R. M. (1997). Social stratification across three generations: New evidence from the Wisconsin Longitudinal Survey. American Sociological Review, 62, 561-572. https://doi.org/10.2307/2657426

Voland, E., \& Beise, J. (2002). Opposite effects of maternal and paternal grandmothers on infant survival in historical Krummhörn. Behavioral Ecology and Sociobiology, 52, 435-443. https://doi.org/10.1007/s00265-002-0539-2

\begin{tabular}{|c|c|}
\hline Italy & 31.6 \\
\hline Austria & 25.6 \\
\hline Spain & 26.1 \\
\hline Portugal & 25.3 \\
\hline Greece & 24.9 \\
\hline Germany & 20.7 \\
\hline United States & 15.7 \\
\hline Luxembourg & 15.4 \\
\hline Switzerland & 11.6 \\
\hline Ireland & 11.1 \\
\hline Canada & 9.2 \\
\hline Norway & 9.0 \\
\hline United Kingdom & 6.8 \\
\hline France & 6.7 \\
\hline Belgium & 6.1 \\
\hline New Zealand & 5.7 \\
\hline Australia & 5.2 \\
\hline Denmark & 4.1 \\
\hline Sweden & 3.6 \\
\hline Finland & 2.6 \\
\hline All & 12.7 \\
\hline
\end{tabular}


Appendix Table 2. Associations between grandparental presence and children's reading literature scores by country ( $\beta$-coefficients from regression model)

\begin{tabular}{|c|c|c|c|c|c|}
\hline & $\beta$ & SE & $\mathrm{t}$ & $\mathrm{p}$ & $\mathrm{R} 2$ \\
\hline \multicolumn{6}{|l|}{ Italy } \\
\hline Grandparent in household & -11.37 & 2.92 & -3.89 & $<0.001$ & 0.22 \\
\hline \multicolumn{6}{|l|}{ Austria } \\
\hline Grandparent in household & -8.96 & 3.58 & -2.50 & 0.013 & 0.26 \\
\hline \multicolumn{6}{|l|}{ Spain } \\
\hline Grandparent in household & -8.48 & 2.67 & -3.17 & 0.002 & 0.25 \\
\hline \multicolumn{6}{|l|}{ Portugal } \\
\hline Grandparent in household & -18.14 & 3.82 & -4.75 & $<0.001$ & 0.27 \\
\hline \multicolumn{6}{|l|}{ Greece } \\
\hline Grandparent in household & -10.77 & 4.23 & -2.54 & 0.012 & 0.21 \\
\hline \multicolumn{6}{|l|}{ Germany } \\
\hline Grandparent in household & -10.28 & 3.88 & -2.65 & 0.010 & 0.31 \\
\hline \multicolumn{6}{|l|}{ Luxembourg } \\
\hline Grandparent in household & -33.94 & 5.05 & -6.72 & $<0.001$ & 0.36 \\
\hline \multicolumn{6}{|l|}{ United States } \\
\hline Grandparent in household & -34.16 & 6.00 & -5.69 & $<0.001$ & 0.27 \\
\hline \multicolumn{6}{|l|}{ Switzerland } \\
\hline Grandparent in household & -33.67 & 3.99 & -8.44 & $<0.001$ & 0.32 \\
\hline \multicolumn{6}{|l|}{ Ireland } \\
\hline Grandparent in household & -27.89 & 6.36 & -4.38 & $<0.001$ & 0.23 \\
\hline \multicolumn{6}{|l|}{ Canada } \\
\hline Grandparent in household & -28.75 & 2.59 & -11.09 & $<0.001$ & 0.20 \\
\hline \multicolumn{6}{|l|}{ Norway } \\
\hline Grandparent in household & -30.13 & 7.31 & -4.12 & $<0.001$ & 0.21 \\
\hline \multicolumn{6}{|l|}{ United Kingdom } \\
\hline Grandparent in household & -41.01 & 5.26 & -7.79 & $<0.001$ & 0.27 \\
\hline \multicolumn{6}{|l|}{ France } \\
\hline Grandparent in household & -36.18 & 6.20 & -5.83 & $<0.001$ & 0.31 \\
\hline \multicolumn{6}{|l|}{ Belgium } \\
\hline Grandparent in household & -52.38 & 5.61 & -9.33 & $<0.001$ & 0.30 \\
\hline \multicolumn{6}{|l|}{ New Zealand } \\
\hline Grandparent in household & -65.31 & 9.25 & -7.06 & $<0.001$ & 0.27 \\
\hline \multicolumn{6}{|l|}{ Australia } \\
\hline Grandparent in household & -29.20 & 6.25 & -4.68 & $<0.001$ & 0.23 \\
\hline \multicolumn{6}{|l|}{ Denmark } \\
\hline Grandparent in household & -38.76 & 8.02 & -4.83 & $<0.001$ & 0.25 \\
\hline \multicolumn{6}{|l|}{ Sweden } \\
\hline Grandparent in household & -54.80 & 9.27 & -5.91 & $<0.001$ & 0.25 \\
\hline \multicolumn{6}{|l|}{ Finland } \\
\hline Grandparent in household & 13.80 & 7.91 & 1.75 & 0.082 & 0.22 \\
\hline
\end{tabular}

